\title{
State Compensation: Relief for Wildlife Infringement
}

\author{
Hong Li \\ School of Law, Changchun University of Science and Technology \\ No. 7989 Weixing Road, Changchun 130022, China \\ E-mail:1h8879@163.com
}

Received: June 20, 2011

Accepted: July 10, $2011 \quad$ Published: October 1, 2011

doi:10.5539/ass.v7n10p295

URL: http://dx.doi.org/10.5539/ass.v7n10p295

\begin{abstract}
According to law, protecting wild animals is every citizen's duty. But when some people are hurt by wild animals, the state compensation is an effective means of relief. At present, China's national compensation system for wildlife violations is inadequate in the aspects of the relief principal, the compensation standard and fund, resulting in unfair or unreasonable compensation for the victims, as should be further improved.

Keywords: Wildlife, Infringement, State compensation

In recent years, because the government has paid great attention to environmental issues and people has strengthened their environmental awareness, the overall situation of wildlife resources in China has improved dramatically. However, events of violating rights of people's life and property have been often appeared in the newspapers. Cases in point are conflicts between man and elephants in Simao City of Yunnan Province, the consumption of sheep by a leopard in Shanxi Province, Jilin Province. Bears or wild boars attacking villagers and destroying crops have been reported repeatedly in Jiaohe and other places in Jilin Province. According to incomplete statistics, by the end of 2010, there had been more than six thousand of compensation cases in the whole China and the direct loss had risen to thousands of yuan. (Cao, 2003, p23). The complementation for relief caused by wild animals against man, livestock and crops has become a serious problem.
\end{abstract}

\section{The basic theory of state compensation}

A proverb in Western law says that, "no relief, no right. Where there is a right there is a relief". Right relief is an approach of correcting and recovering rights and interests after one private right is violated by another private right or public power, the formation of the right correction, interest recovery methods. And the state compensation is an effective way to remedy violations by the wildlife.

The state compensation is a system when legal rights and interests of citizens, legal persons or other organizations are violated when the state administrative bodies or their staff legally practice the state power or maintain the public interests, they can get appropriate compensation from the state according to law. (Shen, 2004, p154). The state compensation aims at filling the victim's loss in particular in order to balance the interests between the victim and other public people.

Otto Meyer, a German jurist, in his special sacrifice theory, believes that when the public interests and personal interest's conflict, personal interests must give way to public interests and make sacrifices. However, it is apparently unfair for the public or an individual citizen to burden for the public interests. Therefore, appropriate compensation should be made for individual citizens who have suffered. Only in this way, can social justice and fairness be restored. According to China's Wild Animal Protection Law, Article 3 provides that wildlife resources belong to the state and protecting wild animals is the obligation of every citizen. Civil Protection of wild animals is to safeguard the public interest. Life or property damage from wild animals is considered to be a special sacrifice. The state making appropriate remedy for the losses suffered by the victim can uphold the legitimate rights and interests of individual citizens and show the principle of social justice as well.

\section{The analysis of the status quo of the state compensation for the infringement by the wild animals}

Article XIV of The Wildlife Protection Act of the People's Republic of China (hereinafter referred to as Wild Animals Protection Law) clearly stipulates that damage to personal life, property or others resulting from the protection of national or local important wild animals should be compensated by the local governments. This is the main legal basis for state compensation for the infringement by wild animals. In addition, there are regulations or special provisions in Inner Mongolia, Hainan and other provinces or autonomous regions. All 
these provisions are in line with the Wild Animals Protection Act. However, they are too abstract to practice.

Different from practice in other regions, in 1998, Yunnan Province took the lead in passing the law of "compensatory approach for damage of life and property caused by important protected terrestrial wild animals in Yunnan Province". Then, such a compensatory approach began to officially practice in Shaanxi Province and Jilin Province. These local regulations define the scope and conditions of compensation, regulate the compensation program and determine the standards of compensation. They have been mobilizing people in the enthusiasm of protecting wild animals and at the same time effectively protect people's vital interests. However, only three provinces in China have enacted the specific compensatory approaches. In practice, no legal basis or hard implementation to law is apparent. Especially, when some provinces deal with the wildlife damage cases, due to inadequate legal basis and other reasons, they have no specific compensation standards and scope. Thus a little money is given mainly from the view point of helping solve difficulties, as seriously violates the legitimate rights of farmers.

Considering China's relevant legislation, there exist some major issues as to the state compensation for wildlife violations as follows:

First, the subject of implementing the relief is uncertain. According to China's Wild Animal Protection Act, damage to crops and others resulting from protecting national and local wildlife should be compensated by the local governments. Obviously, "local government" is the subject undertaking the obligation of compensation. However, according to China's Wild Animal Protection Law, wildlife resources belong to the state. That is to say, the state has the ownership of wild animals. And the local people's governments at all levels exercising the management of the wildlife resources on behalf of the state are not the real owners of the wildlife resources in the local region. According to the theory of property, "those who enjoy the benefits and those who receive benefits bear the responsibility". It is apparently unfair to stipulate the local people's governments, who are not the owners of the wildlife to pay the bills of the damage. Meanwhile, What does the "local governments" really refer to, the provincial government, municipal government or county or town government? The unclear definition of "local government" leads to the buck-passing among the local governments at all levels in actual compensation process, as seriously damages the rights of the victims.

Secondly, the compensation standards are of great difference. As the situations about the damage to people by wild animals are complicated, a unified compensation standard is needed to determine the amount of compensation. But the law has no provision at the present. As far as the whole country is concerned, there is a standard only in the "compensation approach for damage to life and property by terrestrial wild animals in Jilin Province". Article 9 in the Compensation Approach prescribes that if crops are damaged, the compensation can be performed according to the local average yield per unit or sixty percent of the market three years ago. As for compensation standard of personal injury, there is provision in the Compensation Approach for Damage caused by terrestrial wild animals in Jilin, Yunnan and Shaanxi Provinces, but the compensation standards are quite different. In detail, Yunnan Province and Jilin Province take the average salary of workers of the previous year in that place as the compensation standard, while in Shaanxi Province, the net income of farmers of the previous year is considered as compensation standard. There is no uniform standard to work out the damages, resulting in more subjective factors in calculating the damages. Much randomness is included when the compensation is paid. It is difficult to be fair for there will exist different amounts of compensation for the same damage.

Finally, there are no enough compensation funds. At present, there are no clear legal provisions about the sources of compensation. And no special compensation funds have been set up by now too. Such words as "compensation should be paid by the local governments" can be seen in Wild Animal Protection Law. It seems that the compensation should be in the charge of the local governments, but where is the money from? In practice, the sources of compensation funds are quite different. Some is financed by the governments, some may be donated by the local businesses, and others may come from the expenditure for local wildlife protection department. In short, the sources of compensation funds are very unstable. In addition, in the places damaged by the wild animals, it is difficult to ensure that compensation can be paid due to the frequent incidents of compensation and the poor financial situation. The compensation task can not be implemented smoothly.

\section{Suggestions about how to improve the state compensation for infringement by the wild animals}

\subsection{Re-define the relief subject}

It should be clearly defined that the responsibility of relief should be undertaken by the state and it is the government that carries out the tasks of relief. Wildlife resources belong to the state and the state has the ownership of the wild animals and is the only obligation subject to carry out the compensation for the damage. The Central People's Government should become the subject of implementing the obligations, and relief mechanism shared by the Central People's Government and local governments should be set up. Specifically, the Central Government and the provincial government bear the primary duty relief and the city and county 
governments undertake the minor relief obligations. As to the ratio of relief, government at all levels can be authorized to develop specific measures of damage according to the actual situations. For example, Article $\mathrm{X}$ in the Compensation Approach of Jilin Province stipulates that compensation for life and property damage and medical expenses are included in the provincial and municipal (county-level) financial budgets. According to financial management system, it should be in the charge of the provincial and municipal or county governments. Medical expenses for personal injury and damage to crops and livestock caused by wild animals should be shared by the provincial and city (county) government with the financial burden of $50 \%$.

\subsection{Scientifically determine the compensation standard}

The standard of figuring out the damage by the wild animals should be regulated legislatively. Only in this way, can the liability of damage be accurately determined to make a reasonable relief to the victims. The standard of calculating the loss must be objective, or it would be difficult to ensure fair and reasonable compensation.

It should be noted that prices of goods will fluctuate in different time and places. Only in the same place and in recent period the prices of similar types of goods can truly reflect the value of the damaged property. So the compensation standard of lost property should be in accordance with the prices of the similar type of goods at the market in the recent period of the same places. "The recent period" generally should be considered as the previous year of the events. The price of the lost property depends on its value. Prices will fluctuate under the market law. Therefore, the prices of the similar type of goods in the same places should be employed to determine the value of the lost property, as is more fair and reasonable.

There are two standards about the personal injury compensation, one is taking the average annual income of workers in the city or county as the standard and the other is taking the net annul income of farmers of the whole province as the compensation standard. Taking into account the victims of wild animals are mostly local farmers and their income is of uncertainty, the annual average income of workers as compensation in the city or county is more reasonable for it is in line with the local economic reality. The compensation should be different because partial loss of ability and all the loss of ability to work should be recognized when personal injury standard is determine.

\subsection{Determine and protect the sources of compensation fund}

The state finance should establish special compensation fund for damage caused by wild animals and put it into national public finances. The four levels of central, provincial, city and county governments should put the compensation into the financial payment plans to ensure that governments at all levels have adequate compensation fund each year. Compensation fund should be managed by a specialized agency and personnel according to specific methods and rules can not be embezzled without permission. The compensation fund can be derived from the higher people's government funding, community fundraising and corporate sponsoring. Other legal means can be explored to raise fund. After compensation fund for damage caused by the wildlife is established, governments at all levels should publicize the task, mobilize and attract more social forces to fund and support the compensation for damage caused by the wildlife.

In short, perfecting the state compensation against the wildlife infringement is of great practical significance to further enhance the wildlife conservation, reasonably make up for the damage by the wildlife to people's life and property, protect human rights and promote the harmonious development between man and nature.

\section{References}

Cao, Shuqing. (2004). Several legal issues on wildlife protection. Hebei Law. Issue 7.

Cheng, Liaoyuan and Wang, Renbo. (2007). Win the sanctification: general theory of rights and relief. Shandong People's Publishing House.

Gao, Erhu and Shen, Wenhui. (2001). How to compensate the damage by wild animals. China Forestry. Issue 7.

Huang, Songlin and Wang, Yuexian. (2006). How to improve the compensation system of wildlife damage. Rule of law and society, Issue 12.

Luo, Haocai. (2004). Equilibrium theory of modern administrative law. Peking University Press.

National Forest Protection Division. (2000). Fifty years of China wildlife conservation. China Forestry Publishing House.

Qiu, Zhixiu. (2006). A legal analysis of wildlife violations. Administration and law, Issue 5.

Shen, Kaiju. (2004). A study of executive compensation act. Beijing: Law Press.

Xiong, Wenzhao. (2000). Modern administrative law principles. Law Press.

Wang, Liming. (2004). Personal of compensation for life injury. China Social Sciences Publishing House. 